\title{
Weighted Effects of Bromocriptine Treatment on Glucose Homeostasis during Hyperglycemic versus Euglycemic Clamp Conditions in Insulin Resistant Hamsters: Bromocriptine as a Unique Postprandial Insulin Sensitizer
}

\author{
Michael Ezrokhi, Shuqin Luo, Yelena Trubitsyna and Anthony H. Cincotta* \\ VeroScience, LLC, 1334 Main Road, Tiverton, RI 02878, USA
}

\begin{abstract}
Background: Postprandial glucose metabolism is deranged in insulin resistant states typified by increased hepatic glucose output and reduced peripheral and hepatic glucose deposition despite elevated plasma insulin levels. And, mounting evidence suggests that postprandial hyperglycemia may potentiate cardiovascular disease. Time-of-day pulsed bromocriptine (a dopamine D2 receptor agonist) administration to insulin resistant animals and humans improves impaired glucose tolerance and post-meal hyperglycemia without raising the plasma insulin level when assayed many hours after bromocriptine has been removed from the circulation. The bromocriptine response of glucose lowering is more prominent after a meal than just before the meal suggesting a "weighted" effect on postprandial glucose metabolism. However, this supposition has never been evaluated under controlled physiological glucose-insulin clamp conditions to verify the existence of such a unique phenomenon.
\end{abstract}

Findings: This study therefore investigated the effects of daily bromocriptine or vehicle administration for 2 weeks on hepatic glucose output and total body glucose disposal during such hyperglycemic versus euglycemic insulin clamp conditions in insulin resistant, glucose intolerant Syrian hamsters. Bromocriptine treatment improved fasting insulin sensitivity (HOMA-IR) by $38 \% P<0.04$ and both total body glucose disposal and hepatic glucose output during the euglycemic clamp by $21 \%$ and $26 \%, P<0.03$ respectively, relative to vehicle treated animals. Importantly, the incremental increase in total body glucose disposal and inhibition in hepatic glucose output under hyperglycemic versus euglycemic conditions was greater $(73 \%$ vs. $40 \%, P<0.001)$ and markedly stronger $(30 \%$ vs. no change, $P<0.002)$, respectively, in bromocriptine versus vehicle treated animals, respectively.

Conclusions: These findings indicate a unique hyperglycemic environment "weighted" effect of bromocriptine on improving glucose homeostasis in insulin resistant animals that is independent of plasma insulin level.

Keywords: Dopamine; Neuroendocrine resetting; Postprandial metabolism

Abbreviations: FDA: Food and Drug Administration; FFA: Free Fatty Acids; HALO: Hours After Light Onset; HGO: Hepatic Glucose Output; HOMA-IR: HOmeostatic Model Assessment Insulin Resistance; QR: Quick Release; SEM: Standard Error of the Mean; SSPG: Steady State Plasma Glucose; T2DM: Type 2 Diabetes Mellitus

\section{Introduction}

Timed daily systemic or intracerebroventricular administration of bromocriptine, a dopamine D2 receptor agonist, to hyperinsulinemic, insulin resistant animals or once daily (morning) systemic administration of bromocriptine-QR, a quick release formulation of bromocriptine to such humans improves fasting hyperinsulinemia and impaired glucose tolerance by simultaneously reducing post glucose challenge plasma glucose and insulin levels [1-4]. However in these studies, fasting plasma glucose reductions in response to such treatment varied from not at all to moderate depending upon the prevailing glucose level. In Type 2 Diabetes Mellitus (T2DM) subjects, such once daily (morning) treatment with bromocriptine-QR, a Food and Drug Administration (FDA) approved quick release formulation of bromocriptine for the treatment of T2DM, reduced postprandial glucose across the three meals of the day and, these postprandial glucose reductions were larger than those observed in the pre-prandial (intermeal) state $[5,6]$. Collectively these findings suggest that the plasma glucose disposal/glucose homeostasis effects of timed bromocriptine administration may be more potent during the postprandial versus fasting state and that such bromocriptine treatment may potentially act as a unique postprandial "weighted" insulin sensitizer. Bromocriptine may somehow improve insulin sensitivity (to the same physiological plasma insulin level) more after a meal or during acute hyperglycemia than during the fasting state, possibly due to its effects on hypothalamic fuel sensing centers [7]. This function would be a unique mode of action among anti-diabetes agents. However, this potential influence has never been investigated and remains yet to be quantified and is the focus of this investigation.

Postprandial glucose metabolism in both liver and muscle differs from that of the fasting state in several respects in both normal and insulin resistant states [8-11]. Total body glucose disposal increases under hyperglycemic-hyperinsulinemic versus euglycemic-hyperinsulinemic

*Corresponding author: Anthony $\mathrm{H}$. Cincotta, President and Chief Science Officer, VeroScience, LLC, 1334 Main Road, Tiverton, RI 02878, USA, Tel: 401816-0525; Fax: 401-816-0524; E-mail: Anthony_Cincotta@veroscience.com

Received January 18, 2012; Accepted February 17, 2012; Published February 23, 2012

Citation: Ezrokhi M, Luo S, Trubitsyna Y, Cincotta AH (2012) Weighted Effects of Bromocriptine Treatment on Glucose Homeostasis during Hyperglycemic versus Euglycemic Clamp Conditions in Insulin Resistant Hamsters: Bromocriptine as a Unique Postprandial Insulin Sensitizer. J Diabetes Metab S2:007. doi:10.4172/21556156.S2-007

Copyright: ( 2012 Ezrokhi M, et al. This is an open-access article distributed unde the terms of the Creative Commons Attribution License, which permits unrestricted use, distribution, and reproduction in any medium, provided the original author and source are credited. 
Citation: Citation: Ezrokhi M, Luo S, Trubitsyna Y, Cincotta AH (2012) Weighted Effects of Bromocriptine Treatment on Glucose Homeostasis during Hyperglycemic versus Euglycemic Clamp Conditions in Insulin Resistant Hamsters: Bromocriptine as a Unique Postprandial Insulin Sensitizer. J Diabetes Metab S2:007. doi:10.4172/2155-6156.S2-007

clamp conditions in normal subjects but this effect is diminished in T2DM as is insulin inhibition of hepatic glucose output (HGO) [9-11]. In the absence of hyperglycemia, insulin stimulated hepatic glucose uptake and storage is minimal but increases over a wide range of increasing plasma insulin concentrations in the presence of hyperglycemia [8-10] and this insulin effect is attenuated in type 2 diabetes subjects [10-13]. Hyperglycemia per se is also capable of increasing whole body glucose disposal and inhibiting HGO (glucose effectiveness) and this effect may also be diminished in T2DM subjects [14]. Postprandial meal/glucose metabolism involves changes in both plasma glucose and insulin levels. Therefore, to determine if bromocriptine's effect on glucose disposal/ homeostasis relative to vehicle treatment is any different during hyperglycemia versus euglycemia, each under equivalent physiological circulating hyperinsulinemic levels (i.e., at insulin levels observed in the post glucose tolerance challenge state), this study investigated the effects of bromocriptine versus vehicle on total body glucose disposal and hepatic glucose production during a (physiological) euglycemic - (physiological) hyperinsulinemic versus a (physiological) hyperglycemic - (physiological) hyperinsulinemic clamp in euglycemic, insulin resistant, glucose intolerant Syrian hamsters.

\section{Materials and Methods}

Bromocriptine mesylate was supplied at no cost by Poli Industria Chimica (Milan, Italy)

\section{Animals and diet protocol}

Male Syrian hamsters (Mesocricetus auratus), obtained from Simonsen Laboratories, Gilroy, CA, were maintained from birth on a 14/10 hour: light/dark daily photoperiod and fed a normal chow diet ad libitum until 16 months of age. Insulin resistant, glucose intolerant animals were divided into two groups ( $\mathrm{n}=7$-8/group) and treated for 2 weeks with bromocriptine $(4.4 \mathrm{mg} / \mathrm{kg})$ or vehicle (i.p.) at 13 hours after light onset (HALO). Body weight and food consumption were recorded during the treatment stage. Such animals of this age, sex and photoperiod exposure have been established to be severely insulin resistant and glucose intolerant $[1,2,15]$. Animal maintenance and all experimental procedures were conducted in accordance with the National Institute of Health Guide for the Care and Use of Laboratory Animals. The experimental protocols were approved by the Animal Care and Use Committee of VeroScience.

\section{Euglycemic-hyperinsulinemic and hyperglycemic-hyperinsu- linemic clamp}

Euglycemic-hyperinsulinemic and hyperglycemic-hyperinsulinemic clamp study procedures were carried out as described previously $[2,16]$. Following two weeks of treatment the carotid artery and jugular vein were cannulated under pentobarbital anesthesia. On the fifteenth day of the study at 6-8 hours after light onset (17-19 hours after the last bromocriptine administration) animals were subjected to a sequential hyperinsulinemic-euglycemic clamp for 60 minutes followed by a hyperinsulinemic-hyperglycemic clamp for an additional 60 minutes (Figure 1). The insulin infusion rate was chosen to establish a "physiological" hyperinsulinemia in these animals, defined as half the maximal plasma insulin level in response to a glucose tolerance challenge [15] to allow for assessment of treatment on HGO. The hyperglycemic clamp level was chosen to establish a "physiological" hyperglycemia in these animals, defined as half of the maximal plasma glucose level in response to a glucose tolerance challenge [15]. The rates of total body glucose uptake and hepatic glucose production were calculated using Steele's equations from plasma samples during the last 20 minutes of each clamp period [17]. HOMA-IR index was calculated according to Abdul-Ghani et al. [18].

\section{Plasma glucose and insulin measurement}

Plasma insulin levels were measured by radioimmuno assay (Linco/Millipore, Billerica, MA) and plasma glucose was measured using a glucokinase assay (OneTouch Ultra glucose monitor, LifeScan, Milpitas, CA).

\section{Statistical analysis}

Results are expressed as means \pm Standard Error of the Mean (SEM). Statistical differences between Bromocriptine and Vehicle treated groups were analyzed using the Student $t$ test (or Wilcoxon test for not normally distributed data as appropriate) for unpaired comparisons among the groups with StatView software version 5.0.1 (SAS, Cary, NC). A $P$ value of $<0.05$ was considered statistically significant

\section{Results}

Two weeks of bromocriptine treatment reduced body weight (from $223.4 \mathrm{~g}$ to $210.4 \mathrm{~g}, P<0.02$ ), while the weight of the vehicle treated animals remained the same (from $222.6 \mathrm{~g}$ to $221.9 \mathrm{~g}, P=0.9$ ), to produce a between group difference in change from baseline body weight of $-12.3 \mathrm{~g}(P<0.001)$ without altering food consumption $(11.0 \mathrm{~g}$ vs. $10.3 \mathrm{~g}$ per day, $P=0.3$ ) as has been repeatedly reported in these animals [1-3]

Fasting plasma insulin level was reduced $35.0 \%$ in bromocriptine vs. vehicle treated animals $(4.8 \pm 0.5 \mathrm{mg} / \mathrm{dl}$ vs. $3.1 \pm 0.4 \mathrm{ng} / \mathrm{ml}, P<$ $0.03)$ however fasting plasma glucose was unaltered $(124 \pm 5 \mathrm{mg} / \mathrm{dl}$ vs. $115 \pm 10 \mathrm{mg} / \mathrm{dl}, P=0.4$ ). The HOMA-IR, an index of hepatic insulin sensitivity under non-clamp fasting conditions [18] was improved from $23.9 \pm 2.6 \mathrm{mg} / \mathrm{dl}^{*} \mu \mathrm{IU} / \mathrm{L}$ to $14.8 \pm 2.9 \mathrm{mg} / \mathrm{dl}^{*} \mu \mathrm{IU} / \mathrm{L}(P<0.04)$ by bromocriptine treatment, in agreement with previous assessments of basal HGO in such treated animals [19]. During the euglycemic clamp, relative to vehicle treated animals, bromocriptine treatment increased glucose disposal rate by $21 \%$ from $20.2 \pm 1.1 \mathrm{mg} / \mathrm{kg}^{*} \mathrm{~min}$ to $24.4 \pm$ $1.3 \mathrm{mg} / \mathrm{kg}^{\star} \min (P<0.03)$ and decreased hepatic glucose output by $26 \%$ from $3.4 \pm 0.4 \mathrm{mg} / \mathrm{kg}^{\star} \min$ to $2.5 \pm 0.1 \mathrm{mg} / \mathrm{kg}^{\star} \min (P<0.02)$. During the hyperglycemic clamp period, relative to the euglycemic clamp period, among vehicle treated animals the glucose disposal rate increased by $40.1 \%$ from $20.2 \pm 1.1 \mathrm{mg} / \mathrm{kg}^{*} \min$ to $28.3 \pm 1.0 \mathrm{mg} / \mathrm{kg}^{*} \mathrm{~min}$ while $\mathrm{HGO}$ did not further decrease. However during the hyperglycemic clamp period, relative to vehicle treated animals, bromocriptine increased glucose disposal rate by $50 \%$ from $28.3 \pm 1.0 \mathrm{mg} / \mathrm{kg}^{\star} \mathrm{min}$ to $42.3 \pm$ $2.1 \mathrm{mg} / \mathrm{kg}^{\star} \min (P<0.0001)$ (Figure $\left.2 \mathrm{~A}\right)$, and decreased hepatic glucose output by $47 \%$ from $3.4 \pm 0.2 \mathrm{mg} / \mathrm{kg}^{\star} \min$ to $1.8 \pm 0.1 \mathrm{mg} / \mathrm{kg}^{\star} \mathrm{min},(P<$

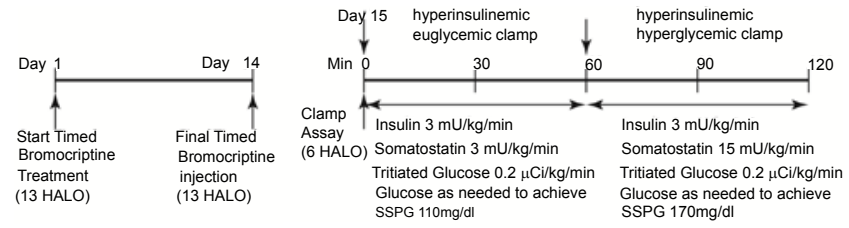

Figure 1: Study design and clamp protocols. Blood samples ( $50 \mu \mathrm{l} \mathrm{each})$ were withdrawn from the carotid at 10-min intervals to determine plasma glucose, insulin, hepatic glucose production and glucose disposal rates. Plasma $\left[3{ }^{3} \mathrm{H}\right]$ glucose radioactivity was measured from the supernatants of barium hydroxide-zinc sulfate precipitates of plasma samples after drying [17]. The rates of total body glucose uptake and hepatic glucose production were calculated using Steele's equations from plasma samples during the last 20 minutes of each clamp period [17]. 
Citation: Citation: Ezrokhi M, Luo S, Trubitsyna Y, Cincotta AH (2012) Weighted Effects of Bromocriptine Treatment on Glucose Homeostasis during Hyperglycemic versus Euglycemic Clamp Conditions in Insulin Resistant Hamsters: Bromocriptine as a Unique Postprandial Insulin Sensitizer. J Diabetes Metab S2:007. doi:10.4172/2155-6156.S2-007

0.0001) (Figure 2B). Insulin levels during each clamp period did not vary between the groups (Bromocriptine: $5.4 \pm 0.5 \mathrm{ng} / \mathrm{ml}$, vehicle $6.5 \pm$ $0.6 \mathrm{ng} / \mathrm{ml}$ ) (Figure 2C).

The incremental increase in glucose disposal rate during hyperglycemia versus euglycemia clamp periods was greater in bromocriptine versus vehicle treated animals when assessed either as change from vehicle control under each clamp condition $(50 \%$ vs. $21 \%$, respectively; $P<0.001$, i.e., more than doubling the increase in disposal rate from euglycemic conditions relative to vehicle control) or as the relative increase from euglyemic clamp conditions versus such relative increase for vehicle treated animals ( $73 \%$ vs. $40 \% P<0.001)$. Likewise the incremental increase in the inhibition of HGO during hyperglycemia versus euglycemia was greater among bromocriptine versus vehicle treated animals when assessed either as change from vehicle control under each clamp condition $(47 \%$ vs. $26 \% ; P<0.001)$ or when assessed as the relative decrease in HGO from euglycemic clamp

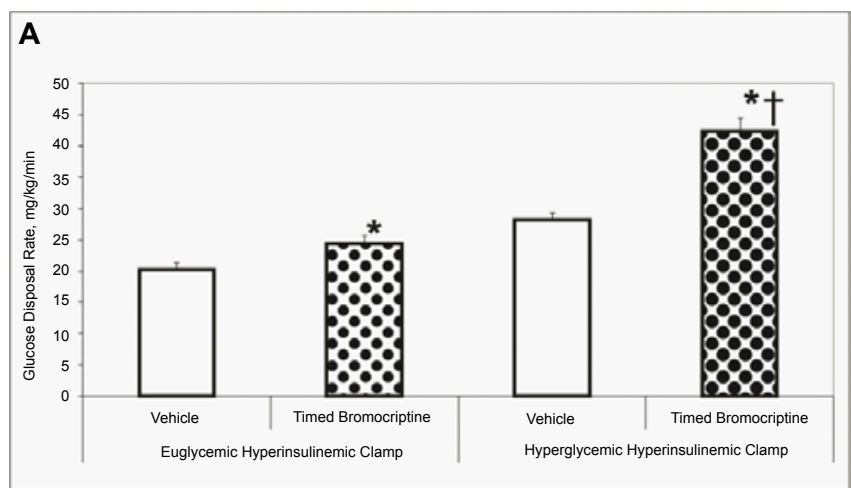

B
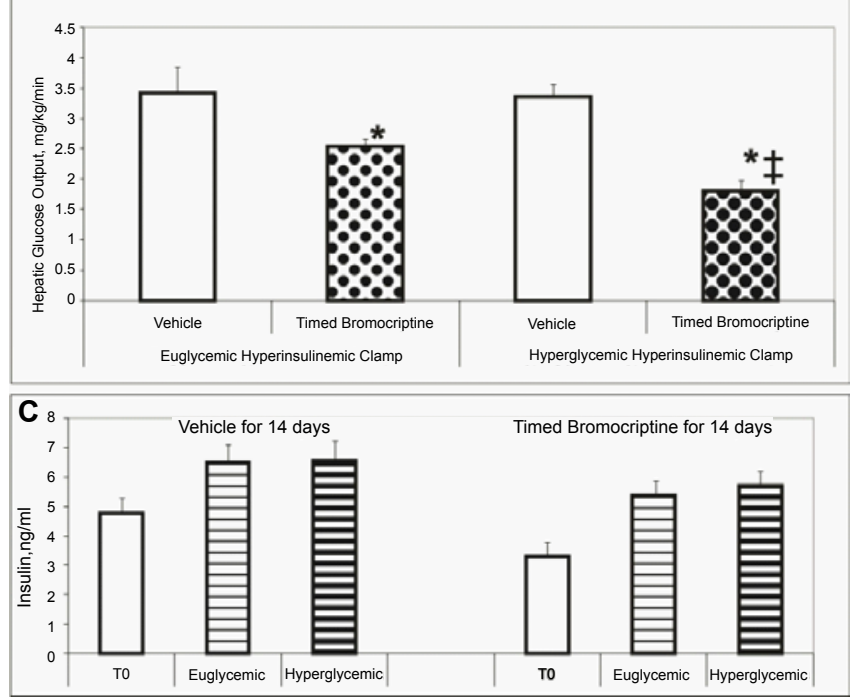

Figure 2: Effect of timed daily bromocriptine on (A) glucose disposal rate and (B) hepatic glucose production during a euglycemichyperinsulinemic clamp and during a hyperglycemic-hyperinsulinemic clamp (C) Plasma insulin levels before (TO) and during the clamps.

*Difference between Bromocriptine and Vehicle treated groups is significant †‡ Incremental change from euglycemic clamp in bromocriptine treated animals is significantly greater than such incremental change for vehicle treated animals (i.e., percent change from euglycemic to hyperglycemic clamp of bromocriptine group result versus percent change from euglycemic to hyperglycemic clamp of vehicle treated group result) (see results section for details) conditions versus such relative decrease for vehicle treated animals (30\% decrease, $P<0.002$ for bromocriptine treated animals vs. no change in vehicle treated animals).

\section{Discussion}

Total body glucose disposal (but not inhibition of HGO) was enhanced under hyperglycemic versus euglycemic clamp conditions in vehicle treated insulin resistant, glucose intolerant animals and the magnitude of this glucose effectiveness and/or increased responsiveness to hyperglycemia, hyperinsulinemia phenomenon has been reported to be diminished in insulin resistant states such as type 2 diabetes $[10,13]$. Relative to vehicle treated animals, at each glucose clamp level, bromocriptine improved glucose homeostasis. However, this study is the first to demonstrate that the incremental increase in total body glucose disposal and inhibition of HGO effects of bromocriptine versus vehicle treated insulin resistant, glucose intolerant animals were each much greater under hyperglycemic versus euglycemic hyperinsulinemic clamp conditions. This unique effect of bromocriptine was manifest a) when examined as compared to vehicle treated animals at each prevailing glucose level (i.e., at clamped euglycemia or at clamped hyperglycemia) or b) when the relative increase in glucose disposal or inhibition of HGO during hyperglycemic versus euglycemic clamp conditions of bromocriptine versus vehicle treated animals was evaluated. The implication here is that mechanisms involved in bromocriptine's beneficial influence on glycemic control/homeostasis in insulin resistant states that act in response to an acute hyperglycemic event such as feeding differ from and are more potent than those acting during fasting euglycemia, and this difference cannot be explained by or is not the result of a change (increase) in insulin during the meal or acute hyperglycemia. How might this unique phenomenon of an increased glucose control effect of bromocriptine during hyperglycemia versus euglycemia (relative to vehicle treated animals) at identical circulating insulin levels occur?

Although the mechanisms responsible for the bromocriptine effect described herein are not delineated in this study, available evidence suggests that this postprandial weighted effect of bromocriptine on glucose disposal in insulin resistance in part involves re-sensitizing brain/hypothalamic fuel sensing system responses to hyperglycemia that are desensitized and as a consequence compound the hyperglycemia in part by sustaining a classic hypoglycemic counterregulatory response (i.e., induce hyperglycemia) even after feeding [15,20-23]. Bromocriptine treatment attenuates this inappropriate overactive hypothalamic drive for increased sympathetic tone to liver in glucose intolerant animals $[2,15,20,22]$ which is a main stimulus for increased HGO and may block hepatic glucose disposal during the postprandial state $[24,25]$. In insulin resistant states, bromocriptine also removes the hypothalamic inhibition of mechanisms known to induce [26-28] vagal stimulation of hepatic insulin sensitivity during the postmeal period $[15,21-23,29]$. Bromocriptine may have, in part as a result of such hypothalamic influences, elicited the effects observed herein by reducing sympathetic tone to liver and adipose, plasma glucagon, cortisol, and/or norepinephrine levels, liver hyper-responsiveness to norepinephrine and/or glucagon, central leptin resistance, muscle and/ or liver lipotoxicity and inflammation (reviewed in [20]).

The relative contribution of muscle versus liver to the increased glucose disposal effect of bromocriptine under hyperglycemic clamp conditions cannot be ascertained from this study. Likewise, the relative impact of bromocriptine on insulin sensitivity, glucose effectiveness, and insulin independent glucose metabolism in manifesting the overall 
Citation: Citation: Ezrokhi M, Luo S, Trubitsyna Y, Cincotta AH (2012) Weighted Effects of Bromocriptine Treatment on Glucose Homeostasis during Hyperglycemic versus Euglycemic Clamp Conditions in Insulin Resistant Hamsters: Bromocriptine as a Unique Postprandial Insulin Sensitizer. J Diabetes Metab S2:007. doi:10.4172/2155-6156.S2-007

effect of bromocriptine to preferentially increase glucose disposal and reduce HGO during the hyperglycemic-hyperinsulinemic clamp cannot be determined from this initial study. However, now that such an effect of bromocriptine has been identified, future studies investigating the specific fractional involvement of each of these physiological activities in producing this bromocriptine response are warranted.

The results of this study indicate that timed daily bromocriptine treatment improves insulin sensitivity by increasing glucose disposal and reducing hepatic glucose output under euglycemic-physiological hyperinsulinemic fasting conditions and that these effects relative to vehicle treatment are much more pronounced under hyperglycemicphysiological hyperinsulinemic clamp conditions. This postprandial "weighted" insulin sensitizing effect of bromocriptine represents a unique mode of action to improve glycemic control in T2DM among available anti-diabetes agents.

\section{Acknowledgement}

\section{Author's contributions}

Michael Ezrokhi, Shuqin Luo and Anthony H. Cincotta contributed to the design, execution, review and writing of this paper; Yelena Trubitsyna contributed to the design, execution and review of this paper.

\section{Funding}

This study was funded by VeroScience, LLC.

\section{References}

1. Cincotta AH, Schiller BC, Meier AH (1991) Bromocriptine inhibits the seasonally occurring obesity, hyperinsulinemia, insulin resistance, and impaired glucose tolerance in the Syrian hamster, Mesocricetus auratus. Metabolism 40: 639644.

2. Luo S, Liang Y, Cincotta AH (1999) Intracerebroventricular administration of bromocriptine ameliorates the insulin-resistant/glucose-intolerant state in hamsters. Neuroendocrinology 69: 160-166.

3. Cincotta AH, Meier AH, Taylor E, Hudson M (1995) Bromocriptine (Ergoset) reduces body fat, hyperinsulinemia, and glucose intolerance in obese subjects. Diabetes 44: s168A.

4. Cincotta AH, Meier AH (1996) Bromocriptine (Ergoset) reduces body weight and improves glucose tolerance in obese subjects. Diabetes Care 19: 667-670.

5. Cincotta AH, Meier AH, Cincotta M (1999) Bromocriptine improves glycaemic control and serum lipid profile in obese Type 2 diabetic subjects: a new approach in the treatment of diabetes. Expert Opin Investig Drugs 8: 16831707.

6. Scranton R, Cincotta A (2010): Bromocriptine--unique formulation of a dopamine agonist for the treatment of type 2 diabetes. Expert Opin Pharmacother 11: 269-279.

7. Jordan SD, Könner AC, Brüning JC (2010) Sensing the fuels: glucose and lipid signaling in the CNS controlling energy homeostasis. Cell Mol Life Sci 67: 3255-3273.

8. Carey PE, Halliday J, Snaar JE, Morris PG, Taylor R (1990) Direct assessment of muscle glycogen storage after mixed meals in normal and type 2 diabetic subjects. Am J Physiol Endocrinol Metab 341: 240-246.

9. Petersen KF, Laurent D, Rothman DL, Cline GW, Shulman GI (1998) Mechanism by which glucose and insulin inhibit net hepatic glycogenolysis in humans. J Clin Invest 101: 1203-1209.

10. Rossetti L, Giaccari A, Barzilai N, Howard K, Sebel G, et al. (1993) Mechanism by which hyperglycemia inhibits hepatic glucose production in conscious rats J Clin Invest 92: 1126-1134.

11. Basu R, Basu A, Johnson CM, Schwenk WF, Rizza RA (2004) Insulin doseresponse curves for stimulation of splanchnic glucose uptake and suppression of endogenous glucose production differ in nondiabetic humans and are abnormal in people with type 2 diabetes. Diabetes 53: 2042-2050.

12. Krssak M, Brehm A, Bernroider E, Anderwald C, Nowotny P, et al. (2004) Alterations in postprandial hepatic glycogen metabolism in type 2 diabetes. Diabetes 53: 3048-3056

13. Basu A, Dalla Man C, Basu R, Toffolo G, Cobelli C, et al. (2009) Effects of type 2 diabetes on insulin secretion, insulin action, glucose effectiveness, and postprandial glucose metabolism. Diabetes Care 32: 866-872.

14. Mevorach M, Giacca A, Aharon Y, Hawkins M, Shamoon H, et al. (1998) Regulation of endogenous glucose production by glucose per se is impaired in type 2 diabetes. J Clin Invest 102: 744-753.

15. Luo S, Meier AH, Cincotta AH (1998) Bromocriptine reduces obesity, glucose intolerance and extracellular monoamine metabolite levels in the ventromedial hypothalamus of Syrian hamsters. Neuroendocrinology 68: 1-10.

16. Cincotta AH, MacEachern TA, Meier AH (1993) Bromocriptine redirects metabolism and prevents seasonal onset of obese hyperinsulinemic state in Syrian hamsters. Am J Physiol 264: E285-293.

17. Beker S (1984) Diagnostic procedures in the evaluation of hepatic diseases. In Wolfe RR, ed. Tracers in Metabolic Research Radioisotope and Stable Isotope/ Mass Spectrometry Methods. Liss, New York: 81-102.

18. Abdul-Ghani MA, Tripathy D, DeFronzo RA (2006) Contributions of $\beta$-cel dysfunction and insulin resistance to the pathogenesis of impaired glucose tolerance and impaired fasting glucose. Diabetes Care 29: 1130-1139.

19. Cincotta AH, Meier AH (1995) Bromocriptine inhibits in vivo free fatty acid oxidation and hepatic glucose output in seasonally obese hamsters (Mesocricetus auratus). Metabolism 44: 1349-1355.

20. Cincotta $\mathrm{AH}$ (2002) Hypothalamic role in Insulin Resistance and insulin Resistance Syndrome. In: Hansen B, Shafrir E, eds. Frontiers in Animal Diabetes Research. Taylor and Francis, London: 271-312.

21. Ezrokhi M, Luo S, Cincotta J, Cincotta AH (2008): Timed dopamine agonist therapy induces a postprandial-selective insulin sensitivity. Diabetologia 51 s276.

22. Luo S, Luo J, Cincotta AH (1999) Chronic ventromedial hypothalamic infusion of norepinephrine and serotonin promotes insulin resistance and glucose intolerance. Neuroendocrinology 70: 460-465.

23. Cincotta AH, Luo S, Zhang Y, Liang Y, Bina KG, et al. (2000) Chronic infusion of norepinephrine into the VMH of normal rats induces the obese glucoseintolerant state. Am J Physiol Regul Integr Comp Physiol 278: R435-444.

24. DiCostanzo CA, Dardevet DP, Neal DW, Lautz M, Allen E, et al. (2006) Role of the hepatic sympathetic nerves in the regulation of net hepatic glucose uptake and the mediation of the portal glucose signal. Am J Physiol 290: E9-16.

25. Cherrington $A D$ (1999) Control of glucose uptake and release by the liver in vivo. Diabetes 48: 1198-1214.

26. Lam TK, Pocai A, Gutierrez-Juarez R, Obici S, Bryan J, et al. (2005) Hypothalamic sensing of circulating fatty acids is required for glucose homeostasis. Nat Med 11: 320-327.

27. Lam TK, Gutierrez-Juarez R, Pocai A, Rossetti L (2005) Regulation of blood glucose by hypothalamic pyruvate metabolism. Science 309: 943-947.

28. Jordan SD, Konner AC, Bruning JC (2010) Sensing the fuels: glucose and lipid signaling in the CNS controlling energy homeostasis. Cell Mol Life Sci 67 3255-3273.

29. Luo S, Ezrokhi M, Trubitsyna Y, Cincotta AH (2008) Intrahypothalamic circuitry regulating hypothalamic fuel sensing to induce insulin sensitivity or insulin resistance. Diabetologia 51: s59. 